See discussions, stats, and author profiles for this publication at: https://www.researchgate.net/publication/224726308

\title{
Influence of isometric voluntary contraction on time and frequency domain parameters of surface EMG
}

Conference Paper $\cdot$ November 2002

DOI: $10.1109 /$ IEMBS.2002.1053348 · Source: IEEE Xplore

\section{CITATIONS}

0

3 authors:

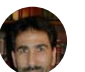

Prodromos Kaplanis

Nicosia General Hospital

30 PUBLICATIONS 211 CITATIONS

SEE PROFILE

Victor Colin Roberts

King's College London

231 PUBLICATIONS 2,447 CITATIONS

SEE PROFILE
READS

29

C. S. Pattichis

University of Cyprus

431 PUBLICATIONS 5,676 CITATIONS

SEE PROFILE

Some of the authors of this publication are also working on these related projects:

GRANATUM "A social collaborative working space semantically interlinking biomedical researchers knowledge and data for the design and execution of in-silico models and experiments in cancer chemoprevention" FP7 Project View project

Motion Analysis of the Carotid Artery View project 


\title{
INFLUENCE OF ISOMETRIC VOLUNTARY CONTRACTION ON TIME AND FREQUENCY DOMAIN PARAMETERS OF SURFACE EMG
}

\author{
P.A. Kaplanis ${ }^{1,3}$, C. S. Pattichis ${ }^{1,2}$, C. V. Roberts ${ }^{3}$
}

${ }^{1}$ Cyprus Institute of Neurology and Genetics, Nicosia, Cyprus Email: p.a.kaplanis@cytanet.com.cy

${ }^{2}$ Department of Computer Science, University of Cyprus, Nicosia, Cyprus Email: pattichi@ucy.ac.cy

${ }^{3}$ Kings College, School of Medicine and Dentistry, University of London, London, UK Email: colin.roberts@kcl.ac.uk

\begin{abstract}
The main objective of this paper was to investigate the effect of increase of isometric voluntary contraction (IVC) on surface EMG recorded from the Biceps Brachii (BB) muscle. Five different force levels (FL) were used: 10, 30, 50, 70 and $100 \%$ of maximum voluntary contraction (MVC), with each recording lasting 5 seconds. The following sets of parameters were extracted: (i) in the time domain (turns (ts) and zero crossings per second (zc)), and (ii) in the frequency domain (median frequency ( $f p$ ), frequency at maximum power $(\mathrm{fx})$, maximum power $(\mathbf{P x})$, and total power $(\mathrm{Pt})$ ). A total of 91 normal subjects aged between 5 and 69 years old were analyzed. The Wilcoxon paired two-tailed test $(p<0.05)$, was used to classify changes in parameters examined as significant (S) or non-significant (NS) during transition from a force level to another. Results showed that: ts, zc, Px, and Pt increase with force whereas $\mathrm{fp}$ decreases with force. Moreover, these parameters showed significant difference between the different force levels examined.

Keywords - Surface EMG, isometric voluntary contraction
\end{abstract}

\section{INTRODUCTION}

Many researchers attempted analysis of surface SEMG. The most frequently examined parameters were mean power frequency (MPF), and to a lesser degree Power Spectrum (PS) shape and total power (Pt). However because results were often conflicting [1]-[5] and group samples examined were small in size, the advantages of SEMG have not been justified that well. The aim of this study is to investigate SEMG simple time and frequency domain parameters on a large group of normal subjects and investigate if they exhibit significant difference at different force levels.

\section{METHODOLOGY}

Ninety-one normal subjects aged between 5 and 69 years of age (54 male (m) and 37 female (f)) participated in this study. The subjects were divided in age groups as follows: $5-9$ years, 12 subjects $(7 \mathrm{~m} \& 5 \mathrm{f}), 10-19$ years, 12 subjects ( $8 \mathrm{~m} \& 4 \mathrm{f}$ ), 20-29 years, 20 subjects $(10 \mathrm{~m} \& 10 \mathrm{f}), 30-39$ years, 13 subjects $(8 \mathrm{~m} \& 5 \mathrm{f}), 40-49$ years, 12 subjects $(7 \mathrm{~m}$ $\& 5 \mathrm{f}), 50-59$ years, 12 subjects $(7 \mathrm{~m} \& 5 \mathrm{f}$ ), and 60-69years, 10 subjects $(7 \mathrm{~m} \mathrm{\&} 3 \mathrm{f})$.

Recording set-up. Frequency settings were $20 \mathrm{~Hz}$ and $500 \mathrm{~Hz}$ for lower and upper cut off frequencies respectively and the sensitivity varied between 10 and $500 \mu \mathrm{V} / \mathrm{div}$, depending on the force level of each individual. The sampling frequency was $1000 \mathrm{~Hz}$ with 16 bits resolution and the duration of the signal recording was 5 seconds. Recording was carried out using a four-bar EMG active probe with an interelectrode distance of $10 \mathrm{~mm}$ and a bar width of $1 \mathrm{~mm}$. The electrode block was placed on the BB in such a way so that the second electrode was at a distance equal with $1 / 3$ of the BB length towards the shoulder. Five different force levels (FL) were used: $10,30,50,70$ and $100 \%$ of maximum voluntary contraction (MVC).

Signal processing. Six parameters were analyzed: two from the time domain (turns (ts) and zero crossings per second (zc)), and four from the frequency domain (median frequency (fp), frequency at maximum power ( $\mathrm{fx}$ ), maximum power $(\mathrm{Px})$, and total power $(\mathrm{Pt}))$. Differences in the mean values of these six parameters were evaluated using the Wilcoxon matched pair rank test. A two-tailed significance level of $95 \%(\mathrm{p} \leq 0.05)$ was used.

Time domain analysis. The number of ts was defined as the number of slope reversals separated from the previous and the following turn by an amplitude difference greater than $10 \mu \mathrm{V}$. The number of $\mathrm{zc}$ was defined as the number of sign reversals exceeding a threshold of $10 \mu \mathrm{V}$.

Power spectral analysis. This was computed by averaging segments of the signal of 512 points with $25 \%$ overlap. The $\mathrm{fp}$ divides the area under the PS area in two equal parts, whereas $f x$ is the frequency at the highest PS peak. The Pt was calculated as the area under the curve and the maximum power $P x$ was estimated as the highest value of the PS curve.

\section{RESULTS}

Table I summarizes the median, and in parenthesis the lower quartile $(25 \%)$ and upper quartile $(75 \%)$ range for all six parameters examined for each force level. The median and lower and upper quartiles are given due to the nonGaussian distribution of the data investigated. Table II summarizes the results of statistical analysis of the Wilcoxon matched pair rank test between different force levels. In Table II, significant difference (S) is given if $\mathrm{p} \leq 0.05$, whereas a non significant (NS) difference is given for $\mathrm{p}>0.05$.

As given in Table $I$ results show that: $t s, z c, P x$, and $\mathrm{Pt}$ increase with force level, whereas fp decreases with force level. Moreover, these parameters showed significant difference between the different combinations of the force levels examined (see Table II). Feature $\mathrm{fx}$ showed significant difference only between 10 and $30 \%$ of MVC.

Figure 1 illustrates the median, lower and upper quartiles spread for each force level of the turns per second and the median frequency. It is clearly illustrated that there is an 
increase of the number of turns per second with force level, whereas the reverse is true for the median frequency.

TABLE I MEDIAN, AND IN PARENTHESIS THE LOWER QUARTILE (25\%) AND UPPER QUARTILE (75\%) RANGE FOR ALL SIX PARAMETERS EXAMINED FOR EACH FORCE LEVEL

\begin{tabular}{|l|l|l|l|l|l|}
\hline \multicolumn{1}{|c|}{} & $10 \%$ & $30 \%$ & $50 \%$ & $70 \%$ & $100 \%$ \\
\hline ts & 34 & 75 & 92 & 105 & 121 \\
& $(3-57)$ & $(28-100)$ & $(55-122)$ & $(70-134)$ & $(88-146)$ \\
\hline zc & 10 & 51 & 73 & 94 & 99 \\
& $(0-44)$ & $(7-81)$ & $(36-102)$ & $(49-108)$ & $(78-116)$ \\
\hline fp & 104 & 101 & 99 & 95 & 93 \\
& $(90-125)$ & $(88-116)$ & $(86-115)$ & $(84-112)$ & $(83-110)$ \\
\hline fx & 76 & 74 & 77 & 75 & 72 \\
& $(64-96)$ & $(63-83)$ & $(67-93)$ & $(65-91)$ & $(64-88)$ \\
\hline Px & 0.24 & 0.92 & 2.8 & 5.03 & 18 \\
& $(0.08-1.2)$ & $(0.28-4)$ & $(0.63-15)$ & $(1.5-31.3)$ & $(3.7-110)$ \\
\hline Pt & 9 & 31 & 85 & 190 & 560 \\
& $(3-3.9)$ & $(7.3-145)$ & $(22-470)$ & $(43-810)$ & $(113-2460)$ \\
\hline
\end{tabular}

TABLE II RESULTS OF STATISTICAL ANALYSIS FOR EACH PARAMETER FOR THE WILCOXON MATCHED PAIR RANK TEST BETWEEN DIFFERENT FORCE LEVELS. SIGNIFICANT DIFFERENCE (S) IS GIVEN IF $\mathrm{p} \leq 0.05$, WHEREAS A NONSIGNIFICANT (NS) DIFFERENCE IS GIVEN FOR $p>0.05$

\begin{tabular}{|l|l|l|l|l|l|l|}
\hline & ts & zc & fp & fx & Px & Pt \\
\hline $10-30 \%$ & S & S & S & S & S & S \\
\hline $10-50 \%$ & S & S & S & NS & S & S \\
\hline $10-70 \%$ & S & S & S & NS & S & S \\
\hline $10-100 \%$ & S & S & S & NS & S & S \\
\hline $30-50 \%$ & S & S & S & NS & S & S \\
\hline $30-70 \%$ & S & S & S & NS & S & S \\
\hline $30-100 \%$ & S & S & S & NS & S & S \\
\hline $50-70 \%$ & S & S & S & NS & S & S \\
\hline $50-100 \%$ & S & S & S & NS & S & S \\
\hline $70-100 \%$ & S & S & S & NS & S & S \\
\hline
\end{tabular}
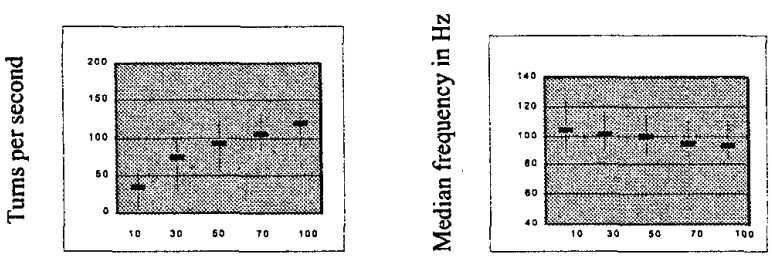

Fig. 1 Median, lower and upper quartiles spread for each force level (shown in the $\mathrm{x}$-axis as percentage of MVC) of the turns per second and the median frequency.

\section{DISCUSSION}

The turns per second and the zero crossings were increased significantly with force for all subjects as well as the maximum and total power extracted from the power spectrum of the signals recorded. The median frequency showed a small but significant decrease in value with force, whereas the frequency at maximum power remained fairly constant with non significant difference between force levels except in the $10-30 \%$ transition.

Although the mean frequency was generally used by most of the studies, in this study the median frequency was selected for the following reasons: (i) it is more reliable when examining signals affected with noise such as SEMG signals [4], (ii) since SEMG signals do not present the characteristics of a normal distribution, median frequency should be preferred [6], and (iii) mean frequency is more influenced from the low pass tissue filtering effect rather than the median frequency [6]. Similar findings to this study regarding the decrease of median frequency with force level were also reported in [7].

The change of the six parameters computed with age and gender was also investigated, however, non significant differences were identified.

The results of these study suggest that simple parameters, like the turns per second, the zero crossings per second, the median frequency, the power at maximum frequency and the total power differ significantly between the different transitions of $10,30,50,70$, and 100 of MVC. These parameters are currently evaluated on SEMG recorded from subjects. suffering with neuromuscular disorders.

\section{ACKNOWLEDGMENT}

This work was made possible through the kind support of the Cyprus Institute of Neurology and Genetics.

\section{REFERENCES}

[1] Chaffin D B, (1969). Surface electromyography frequency analysis as a diagnostic tool, Journal of Occupational Medicine, Volume 11 No 3.

[2] Gander R E, Hudgins R E, (1985), Power spectral density of the surface myoelectric signal of the biceps brachii as a function of static load, Electromyography Clin. Neurophysiology 25: 169-178.

[3] Hagberg M, Ericsson B-E, (1982). Myoelectric power spectrum dependence on muscular contraction level of elbow flexors. Eur. J. Physiol., 48: 147-156.

[4] Merletti R, De Luca C J, (1989). New techniques in surface electromyography, in computer aided electromyography and expert systems, edited by Desmedt $J$ E, Elsevier, vol.2, Amsterdam-New York-Oxford, chapter 9, section III, 115-124.

[5] Rainoldi 1, Galardi G, Maderna L, Comi G, Conte L L, Merletti R, (1999), Repeatability of surface EMG variables during voluntary isometric contractions of the biceps brachii muscle, Journal of Electromyography and Kinesiology 9:105-119

[6] Bilodeau M, Cincera M, Gervais S, Arsenault A B, Gravel D, lepage Y, Mckinley P, (1994), Changes in the electromyographic spectrum power distribution caused by a progressive increase in the fore level, Eur. J. Appl. Physiol. 71: 113-123

[7] Haig J A, Gelblum J B, Rechtien J J, Gitter A J, (1999), Technology review: The use of SEMG in the diagnosis and treatment of nerve and muscle disorder: Muscle and Nerve 22:Supplement 8:S239-S242 